\title{
European influence in ITU-R: The end of an era of dominance?
}

M Mohamed Ali Elmoghazi Ali, Jason Whalley, James Irvine, University of Strathclyde

\section{Introduction}

Since its establishment in 1865, the International Telecommunications Union (ITU) has been considered by many as a European organisation. Firstly, the ITU was originally established as the outcome of an agreement between 20 European states to ensure interoperability between international telegraph networks (Zacher, 1996). While other members joined the ITU later, the organisation was mainly controlled prior to 1950 by a small number of European countries that used the votes of their colonies in Africa and elsewhere to support their positions (Ryan, 2012). A second reason is that the United States used to believe that the ITU favoured the European position of enforcing a government monopoly in the telecommunications sector (Ryan, 2012). Thirdly, the conflict of interest with regard to spectrum allocation between the different radiocommunication services led to dividing the world into Europe and "other regions" by the Radio Sector of the ITU (ITU-R) in 1938. This was further developed in 1947 into the current three regions systems of spectrum allocation where the European countries lie in Region 1 with the African and Arab countries and the United States lies in Region 2 (Mazar, 2009). Since then, the ITU tended to be more global as it became a specialised United Nation (UN) agency in 1947(Shahin, 2011).

However, recent years have witnessed the rise of the Arab and African countries in the ITU-R. The conflict between European and other (Arab and African) countries in Region 1 at the last World Radiocommunication Conference of 2012 (WRC-12) was quite significant, with the Arab and African countries calling for an immediate allocation of spectrum in the 694-790 MHz band to mobile service, which was already allocated to broadcasting service, to meet growing broadband demand. The European countries opposed such proposal, not least due to the political pressure from their broadcasters and argued that the issue was not on the agenda of WRC-12 and had not been studied by ITU-R. A compromise was, however, reached of considering the allocation effective immediately after WRC-15.

\section{Understanding WRC dynamics}

The most recent WRC suggests that European influence is declining. In order to determine whether this is the case, a qualitative methodology was adopted that examined the activities of African, Arab, Asian and European countries in various ITU-R working parties at previous WRCs. To focus the analysis, particular attention was paid towards the discussion over the $700 \mathrm{MHz}$. Such a strategy requires conducting a detailed investigation of specific case(s) in order to obtain a closer insight into the context and processes involved in the research subject (Meyer, 2001). Moreover, case studies can ensure accuracy, facilitate the emergence of alternative explanations and can bring out more details through using multiple sources of data (Tellis, 1997).

The article is based on primary data collected from 27 semi-structured interviews of an average length of 45 minutes with the main stakeholders that participated in the last WRC12. Interviewees include delegates from the different ITU-R regional organisations (European Conference of Postal and Telecommunications Administrations (CEPT), the Asia Pacific Telecommunity (APT), the Inter-American Commission of Telecommunications (CITEL), 
the Arab Spectrum Management Group (ASMG), the African Telecommunications Union (ATU), and the Regional Commonwealth in the field of Communications (RCC)), national regulatory agencies in the European, African, and Arab countries, ITU-R Bureau (BR), and many representatives from the industry. Moreover, interviewees were partially identified based on the participation of the first author for several years in the ITU-R. A list of different topics and related questions were prepared and selected for each group of interviewees based on their background. In addition, most interviews were recorded upon permission of the interviewees and notes were also taken during the interviews. For confidentiality reasons, the names of the interviewees are not disclosed. The article also draws on secondary data illustrating the contributions of the European, Arab and African countries in the ITU-R.

The difference between unstructured and semi-structured interview is that the former is similar to a conversation and could contain one question, while the later compromises a list of questions on specific topics (Bryman and Bell, 2007). On the other hand, structured interviews have a rigid structure that cannot be easily modified (Bryman and Bell, 2007). Interviews were selected for different reasons (Saunders et al., 2009). Firstly, they enable the researcher to build on their responses. Secondly, personal contact assures achieving more response rate as interviewees may hesitate to provide sensitive data or to spend time explaining their answers. Other data collection methods were also considered such as questionnaires. However, questionnaires have the disadvantage of potential low response rate. They also require knowing all the possible answers for each question. Moreover, questionnaires are not a flexible collection data method (Saunders et al., 2009).

The rest of the article is organised as follows. Section Three explores preparations regarding WRCs in Region 1, and then section Four traces the origin of the $700 \mathrm{MHz}$ issue. Section Five examines the $700 \mathrm{MHz}$ issue during and after WRC-12, and then section Six is a general analysis of the $700 \mathrm{MHz}$ issue in an attempt to provide explanations to specific events. Section Seven discusses the policy implications of the $700 \mathrm{MHz}$ issue, while conclusions are drawn in the final section.

\section{WRCs Preparation in Region 1}

WRC is one of the ITU-R conferences ${ }^{1}$ that consider specific radiocommunication matters. Regional organizations usually present common proposal to WRCs on behalf of their member states as proposals must have the support of more than one administration to be considered (Contant and Warren, 2003). There are six regional organisations in the ITU-R namely CEPT, ASMG, APT, ATU, CITEL and RCC. It is argued that regionalisation emerged as a reaction to the globalisation process (Lin, 2003).

CEPT is the main regional group that represents the European countries in the ITU-R and it was founded in 1959 to discuss telecommunications issues including spectrum management (Ryan, 2005). It is out of the scope of this article to assess the efficiency of the decision making procedures in CEPT with regard to WRCs. However, we can describe them with confidence as complex. Firstly, regarding the preparation for WRCs, Conference Preparatory Group (CPG) is responsible of developing European Common Proposals (ECPs) for WRCs. ECPs are adopted if there are at least ten supporting administrations and not more than six opposing administrations (RSPG, 2009). Secondly, with regard to the interaction with the EU, CEPT has 48 members with 28 of them from the EU. Regarding WRCs, the EC

${ }^{1}$ Other conferences include Radio Assemblies (RA), Regional Radio Conferences (RRC), and Conference Preparatory Meetings (CPM). 
can attend ITU meetings as an observer (Shahin, 2011). Moreover, the EU member states coordinate to have one proposal on behalf of the EU (European Commission, 2011).

Thirdly, the presence of some members from RCC (Azerbaijan, Belarus, Georgia, Moldova, Russian Federation, and Ukraine) in CEPT (CEPT, 2013; UPU, 2013) could be more problematic. More specifically, although it seems that RCC do not block the discussion at CEPT with regard to ECPs of WRCs, they may raise the conflict at the WRC level and take direct opposition to CEPT positions as was indicated in several interviews ${ }^{2}$. In addition, the RCC countries, which are member of CEPT, can also participate and influence the discussion at CEPT to a certain limit.

Fourthly, the interaction of main CEPT countries with other countries in Region 1 needs to be examined. For instance, France has a strong presence and influence in the International Organisation of La Francophonie which accommodates 77 member states and governments (57 members and 20 observers) including 32 African countries and 7 Arab countries (International Organisation De La Francophonie, 2013). France cooperates with the Francophonie countries in telecommunication through the Administrative Conference of Posts and Telecoms of French-speaking countries (CAPTEF) and Francophone Telecoms Regulatory Network (FRATEL) (Mazar, 2009). Moreover, UK is a main member in the Commonwealth Telecommunications Organisation (CTO) which also accommodates several Arab and African countries (Mazar, 2009). CTO is an international development partnership between Commonwealth and non-Commonwealth governments, business and civil society organisations (The Commonwealth, 2013).

While CAPTEF does not have official committee for WRC preparation, it is known that African Francophonie countries usually have a meeting in Paris shortly before WRCs. However, there is no available published information on that. On the other hand, CTO established the Commonwealth ITU Group (CIG) in 2002 which accommodated 54 countries including 18 African countries (CIG, 2013). Eventually, CTO and CAPTEF are not recognised regional groups by the ITU-R in terms of WRCs preparations. Instead, they are global organisations for cooperation and views exchange as they accommodates countries from the three regions of the ITU-R.

All of the previous show how the decision making procedures with regard to WRCs in the European countries are quite complicated and accommodate several entities which require extensive coordination. It also compromises different countries with different interests and connections outside CEPT such as RCC, CAPTEF, and CIG. In addition, WRCs positions are largely influenced by the EU policy. On the other hand, the following section shows how the situation is different for the Arab and African countries.

Firstly, the Arab world consists of twenty two Arabic speaking countries (The World Bank, 2011) and they are a mix of six developed and sixteen developing countries with diverse range of population and GDP per capita (The World Bank, 2012; UNData, 2012a; UNData, 2012b). The Arab countries have a regional group, ASMG that is responsible for coordinating Arab States positions in ITU meetings (ITU-R, 2010). ASMG was created in 2001 by the Arab Council of Telecommunications and Information to manage and coordinates all issues related to spectrum management. The first WRC that ASMG participated in was WRC-03 (ITU-Arab Regional Office, 2003). ASMG usually meets at

${ }^{2}$ One of the recent issues that noticed a clear conflict of interest between CEPT and RCC is related to the WRC-12 Agenda Item 1.17 which addresses the sharing studies between the mobile service and other services in the band 790-862 MHz in Regions 1 and 3. More specifically, there was an extensive discussion on the compatibility between mobile service operating in CEPT countries and Aeronautical Radionavigation service operating in neighboring RCC countries. Eventually, they had to reach a compromise (Fournier, 2011a). 
least once per year in the period priors to WRC, and preparation for WRCs includes assigning coordinators and supporters for each of the WRC agenda items (ASMG, 2010). Secondly, the ATU was established in 1999 and it accommodates 44 Member States and 16 Associate Members (ATU, 2013b). ATU usually organises two or three preparatory meetings before WRC and preparations include African sub-regional groups such as Southern African Development Community (SADC) and East African Community (EAC). In general, the ASMG and the ATU are the most recent established regional organisation in the ITU-R comparing to other regional organisation (CEPT was established in 1959, APT was established in 1996, CITEL was established in 1993, RCC was established in 1991) (APT, 2013; Chaduc and Pogorel, 2008; RCC, 2013; Ryan, 2005).

While there is no available information on the procedures for reaching common positions for WRCs in the Arab and African countries, the preparation for the last WRC-12 gives an indication that reaching agreement is relatively easier to achieve in these countries comparing to the European countries. In other words, if we consider the relatively large number of the Arab and African countries and the small number of meetings they have prior to WRCs to prepare common positions, this gives an indication of the level of consensus. For instance, the European countries' preparation for WRC-12 accommodates two RSPG opinions, joint EC/CEPT workshop, commission communication, and council conclusions (Fournier, 2011) and CPG met for 8 times (CEPT, 2011). On the other hand, ASMG met for six times and ATU met for three times prior to WRC-12 (ITU, 2011). Furthermore, the ATU common positions for WRC-12 show that most of the African countries did not have a position regarding most of the conference agenda items (ATU, 2011a).

As explained by several interviewees "We wake up in Conference Preparatory Meeting (CPM) and then attend WRC ...before 1992, you never heard an African country speak". This could be explained by the absence of interest by the African and Arab countries in many of the WRC's agenda items which are related to topics such as amateur and science services. In addition, these countries are not industrial ones; therefore, they don't have national champions from the industry to support. Moreover, having common background in terms of language and culture may have an influence on reaching common positions in general.

\section{The Origin of the $700 \mathrm{MHz}$ Issue}

In order to understand the origin of the $700 \mathrm{MHz}$, it is important to explore the agenda item 1.4 of the WRC-07 which considered frequency-related matters for the future development of International Mobile Telecommunication-2000 (IMT-2000) and systems beyond IMT-2000 (ITU-R, 2003). Two of the bands that were under examination in the conference are 806-862 MHz and 470-806 MHz. During the WRC-07, the African countries did not support the identification of the 470-806 MHz band for IMT systems and supported the band 806-862 MHz instead (ATU, 2007). On the other hand, the Arab countries did not have common proposal on this agenda item (ASMG, 2007). The European position was different. CEPT proposed no change in band $470-862 \mathrm{MHz}$ at WRC 07 and to discuss the issue at the next WRC (CEPT, 2007).

WRC-07 decided to identify the 698-862 MHz band in Region 2 and nine countries of Region 3 and the 790-862 MHz band in Regions 1 and 3 for IMT (Politis and Wijting, 2010). WRC-07 decided also to invite ITU-R to conduct sharing studies for Regions 1 and 3 in the band 790-862 $\mathrm{MHz}$ between the mobile service and other services in order to protect 
the services to which the frequency band is already allocated (ITU-R, 2007c). Accordingly, one of the agenda item of the WRC-12, agenda item 1.17, addressed such issue (ITU-R, 2007b) and a Joint Task Group (JTG 5-6) was established between Study Group 6, which is concerned with broadcasting services, and Study Group 5, which is concerned with mobile services (ITU-R, 2007a). The results of these studies at the WRC-12 showed that no new mandatory regulatory measures are needed to enable sharing between mobile and broadcasting services in neighbouring countries in the 790-862 MHz band (Ofcom, 2012b).

Following WRC-07 and before WRC-12, the European broadcasters showed great resistance in general to the allocation of mobile service in the UHF spectrum band which is already allocated to the broadcasting service arguing that such allocation would restrict introducing new TV services such as 3D TV and HDTV and it was pointed out that $60 \%$ of European households receive their TV services from terrestrial television (Broadcast Networks Europe, 2011). It was also argued that such allocation would constrain the operation of services such as PMSE (Programme Making and Special Events) (Association of Professional Wireless Production Technologies (APWPT), 2012). Moreover, it was explained that the result of agenda item 1.17 will not be applicable to the band $470-790 \mathrm{MHz}$ (Broadcast Networks Europe, 2011). In addition, it was pointed out that GE06 plan may not be sufficient to protect broadcasting service at the 790-862 MHz band (EBU, 2011).

The $700 \mathrm{MHz}$ proposal was discussed and initiated very shortly before the conducting of WRC-12 in January 2012. Firstly, it was a proposal from UAE at the end of 2011 that was supported by few Gulf countries, namely Qatar and Kuwait (UAE et al., 2011). The proposal was promoted by several entities from the industry in the ATU 1st African summit on digital dividend that was held in November 2011 (Kirkaldy, 2011; Lyons, 2011). The summit recommended later to pursue the allocation of the band $694-790 \mathrm{MHz}$ to mobile service on an equal primary basis with broadcasting for African Countries at the WRC-12 (ATU, 2011b). Additionally, the mobile industry lobbied regional organizations of the African and Arab countries prior to WRC-12 (Billquist, 2010a; Billquist, 2010b).

It seems also that the idea of a second digital dividend in the $700 \mathrm{MHz}$ was discussed on a small scale in the European countries shortly before the conference but it was well recognised by the industry and ITU officials that this would be controversial and unwelcomed as it will disturb the broadcasting plans in the band (Mobile Europe, 2012). Instead, the European countries were heading into having an agenda item in the WRC-15 (Cullen International, 2011).

\section{World Radiocommunication Conference 2012}

During the first days of WRC-12, the Arab and African countries called for an immediate allocation of spectrum in the $694-790 \mathrm{MHz}$ band to mobile service, which was already allocated to broadcasting service, to meet growing broadband demand. The proponents of the issue were arguing that the issue could be addressed under the WRC-12 agenda item 1.17 and their main argument is that the technical coordination condition between the mobile and broadcasting service at the $800 \mathrm{MHz}$ could be applied at the 700 $\mathrm{MHz}$ without the need of another agenda item at future conference.

More specifically, the Arab countries submitted an official contribution under agenda item 1.17 shortly before the WRC-12 supporting the issue and calling for harmonisation of allocations in the band $698-790 \mathrm{MHz}$ in the three regions of the ITU-R (ASMG, 2011). The African countries also promoted the allocation and explained that the band $790-862 \mathrm{MHz}$ is 
partially allocated to other services in many African countries which increases the importance of the band 694-790 MHz (ATU, 2012). The main proponents of the issue during the conference were UAE, Egypt, and Nigeria. Egypt submitted a statement entitled "Motivations of getting an extension for mobile spectrum allocation in 700 band (698-790 $\mathrm{MHz}$ ) during WRC-12 and not later" (ITU-R, 2012c). Moreover, Nigeria submitted a contribution during the conference supporting the $700 \mathrm{MHz}$ proposal and recalling that the African countries are a majority in Region 1 (Nigeria, 2012).

The argument presented by Arab and African countries was based on a number of points (ITU-R, 2012c). Firstly, the spectrum available in the 790-862 $\mathrm{MHz}$ band for mobile broadband is only the band $790-816 \mathrm{MHz}$ as the rest of the band is already used by other services. Therefore, the 694-790 MHz band is, for the Arab and African countries, arguably the first digital dividend rather than the second. Secondly, the 694-790 MHZ band is already allocated in ITU Regions 2 and 3 for mobile and using this band will decrease the cost of deploying such systems. Finally, the propagation characteristics of the 694-790 MHz band will contribute to reducing the digital divide between developing and developed countries.

The CEPT countries opposed the $700 \mathrm{MHz}$ proposal arguing that the band is heavily utilised by broadcasting service and that there are already long-term licensing arrangements (ITU, 2013b). The RCC countries also opposed the $700 \mathrm{MHz}$ proposal arguing that such allocation would require a further coordination in border countries that are part of the GE06 plan and that no research had been conducted on the broadcasting service spectrum requirements nor on compatibility with aeronautical radionavigation systems (ITU, 2013b).

The interviewees describe in different ways the reaction of the European countries to the Arab and African proposal. One interviewee explains that "the European countries were annoyed because they felt that for the first time they are not in control". Also one of the reasons why the European countries' reaction was late is that the 700 proposal was initiated very shortly before the WRC-12 and after the last CPG meeting so there was no possibility to discuss the issue before the conference at the CEPT level. Some interviewees explain how that several European countries were shocked by the $700 \mathrm{MHz}$ proposal and delegates had to travel to their home countries during weekends to seek advice from their ministers. In addition, as the issue was not on the agenda of the conference, many of the concerned broadcasters were not present at the discussions. The interviews show also that although CEPT clearly opposed the $700 \mathrm{MHz}$ proposal during WRC-12, there was not consensus among the European countries during the conference on the issue and that some of the European regulators were in sympathy with the $700 \mathrm{MHz}$ proposal.

As the discussion was developed further through the conference, the African countries were defending the RCC and CEPT resistance explaining that the African countries will not cause interference to the European countries. The discussion was going to a decision based on voting. However, the results of voting are not expected in general and if the decision of the voting was against the European countries will, this would significantly weaken the credibility of the European countries in the ITU-R in general and in Region 1 in particular.

WRC-12 decided eventually to allocate the $694-790 \mathrm{MHz}$ band in Region 1 to mobile service on a co-primary basis. The allocation is effective immediately after WRC-15 upon refinement of the lower edge of the allocation which is subject to ITU-R studies regarding channelling arrangements for mobile services (ITU-R, 2012b). While CEPT agreed eventually to the $700 \mathrm{MHz}$ allocation, several European countries recorded their reservation and stated that they agreed to reach a compromise with great reluctance and on an exceptional basis in the spirit of international cooperation and to satisfy the urgent demand of the African and Arab countries. They also stated the WRC-12 did neither discuss nor clarify, 
whether the proposals belong to one of the Agenda items of the WRC-12 Agenda (Oberst, 2012).

The official views of CEPT after WRC-12 consider that the conference decision took into account the need for European countries to better study the issue before taking a final position on the best suitable allocation and associated regulation, and that it gave CEPT countries the flexibility whether to utilise the band for broadcasting or mobile service while preserving Geneva-06 Agreement (Fournier, 2012). In addition, the European countries acknowledged the existing use of the $700 \mathrm{MHz}$ in the ITU-R three regions (RSPG, 2012).

It seems that the European countries were not upset with the results of the WRC-12 and they even adapted well to it. As stated by the head of RSPG "Europe was relatively cautious at first about freeing up the $700 \mathrm{MHz}$ band for IMT services but followed "quite happily" after Arab and African countries pushed for it at WRC-12" (Standeford, 2012a). The UK, for instance, was planning to use the $700 \mathrm{MHz}$ spectrum band for digital terrestrial TV (DTT) while allowing the use of white spaces technologies (Ofcom, 2012a). However, following the WRC-12 decision, the UK is currently considering utilizing the $600 \mathrm{MHz}$ as part of a frequency re-plan of the DTT platform after the $700 \mathrm{MHz}$ spectrum is released for mobile broadband (Ofcom, 2012a).

Furthermore, following the WRC-12, the ITU-R established the Joint Task Group (JTG) 4-5-6-7 to address the sharing and compatibility between broadcasting and mobile services at the $700 \mathrm{MHz}$ band among other issues (Stirling, 2012). One issue that was raised in the JTG 4-5-6-7 is how to harmonise the different frequency arrangements among the three ITU-R regions (Rancy, 2012). In Europe, CEPT has adopted a plan in the $800 \mathrm{MHz}$ that operates in the bands $791-821 \mathrm{MHz}$ and $832-862 \mathrm{MHz}$ and provides $2 \times 30 \mathrm{MHz}$ for FDD operation of broadband systems. In addition, the USA adopted a more complicated plan that compromises a mix of FDD operation in the bands $698-716 \mathrm{MHz}, 728-746 \mathrm{MHz}, 746-763$ $\mathrm{MHz}$, and 776-793 MHz and TDD operation in the band 716-728 MHz (ITU-R, 2012a). On the other hand, in Asia, the APT has adopted a plan in the $700 \mathrm{MHz}$ that operates in the bands 703-748 MHz and 758-803 MHz and provides 2x45 MHz for FDD operation of broadband systems (APT, 2010). The APT plan is different than the other plans because it compromises dual-duplexer arrangement with $2 \times 30 \mathrm{MHz}$ for each one (APT, 2010). The reason for adopting dual-duplexer is that the maximum bandwidth of a duplexer for a terminal at this frequency range is usually around $30-35 \mathrm{MHz}$ (APT, 2009). Therefore, it is difficult to have a user handset that covers the $2 \times 45 \mathrm{MHz}$ of the APT plan with only one duplexer.

Having mentioned that, it is important to recall that the main incentive for the Arab and African countries for proposing the $700 \mathrm{MHz}$ allocation in the WRC-12 was to harmonise their spectrum plans with Regions 2 and 3, specifically the APT plan in Region 3. However, the APT plan overlaps with the CEPT plan in the band 791-803 MHz which means that countries cannot adopt both of the two plans in the same time and a choice between them has to be made. If a country adopts the CEPT plan, it will not be able to utilise the large bandwidth of the APT plan in the $700 \mathrm{MHz}$. On the other hand, fully adopting of the APT plan would impact the harmonisation with CEPT plan.

With the confidence that the Arab and African countries acquired in the WRC-12, they proposed different frequency arrangements in order to maximise the utilisation efficiency of the band 694-790 $\mathrm{MHz}$ even if that contradicts with the CEPT plan. For instance, one proposal was to fully harmonise the frequency arrangement of the $700 \mathrm{MHz}$ in Africa with the APT plan and adopt a plan of $2 \times 45 \mathrm{MHz}$. Such proposal overlaps with the CEPT plan and focuses only on protecting the broadcasting service in the $470-694 \mathrm{MHz}$ band. Other proposals were to partially harmonise the frequency arrangement in the Arab and 
African countries with the APT plan and to adopt arrangements such as $2 \times 40$ and $2 \times 42$. There were even other proposals that do not overlap with CEPT plan but also do not harmonise with none of the two duplexer of the APT $700 \mathrm{MHz}$ band plan. Moreover, some proposals from the industry, mainly from Europe, overlapped with the broadcasting plan in the upper part of the 470-694 MHz band (WP 5D Chairman, 2013b). Most of these proposals were withdrawn later (WP 5D Chairman, 2013a), and the focus changed to be on achieving frequency arrangements that could fit with the CEPT plan and partially with the APT plan while having one duplexer in the users handset. This will achieve economy of scales as handsets will be able to roam around the different regions with minimum number of duplexers.

\section{Discussion}

One of the issues that need an explanation is the preliminary European refusal to the $700 \mathrm{MHz}$ proposal at the early days of WRC-12 and then the agreement to the proposal at the end of the conference. Firstly, the interviews indicate that one of the reasons of the European refusal is that the process of releasing the band $790-862 \mathrm{MHz}$ to mobile service in the European countries was quite slow and costly (Stirling, 2012). Therefore, the European countries were unwilling to go through another dispute with their broadcasters and preferred to postpone the discussion "they were unwilling to open the box and preferred to leave it closed". In addition, European operators were not in rush for the $700 \mathrm{MHz}$ allocation as they are still in the process of launching their services in the $800 \mathrm{MHz}$ and other measures could be used to meet the growth in demand such as Wi-Fi offloading (Stirling, 2012). Furthermore, several European network operators are facing severe competition in the European market in addition to the saturation of subscribers number (Fransman, 2010). The allocation of new spectrum in the $700 \mathrm{MHz}$ may lead to new entrants which will make the situation worse for the existing operators.

So why there was diversity in the European views over the issue during the conference? Firstly, the internationalisation of European telecom operators (e.g. Deutsche Telekom, Vodafone) and the fact that many European countries have international manufactures (e.g. Sweden's Ericsson, France's Alcatel, and Germany's Siemens) (Ryan, 2005), may have motivated some of the European countries to reconsider their position during the conference. More specifically, the European countries have eight international mobile network operators out of eighteen worldwide (Fransman, 2010). This motivates these international operators to seek more harmonisation among the ITU-R three regions, and to have more spectrum identified to IMT systems in lower spectrum bands for coverage (e.g. $700 \mathrm{MHz}$ and $800 \mathrm{MHz}$ ) and in higher spectrum bands for capacity $(2.3 \mathrm{GHz}$ and $2.6 \mathrm{GHz})$. In addition, the European countries have different needs with regard to terrestrial broadcasting service (Cullen International, 2011). For instance, Belgium depends more on Cable TV while Germany has high penetration of satellite TV. On the other hand, France has high dependency on DTT. This may explain the struggle within Europe during the WRC-12 regarding the $700 \mathrm{MHz}$ issue as some administrations wanted to re-farm and auction the 700 $\mathrm{MHz}$ band in the future while others had a pressure from their broadcasters. One other reason that was revealed by the interviews is that the idea of re-farming the $700 \mathrm{MHz}$ for mobile use in several European countries was under consideration by different administrations. However, the timing was not at the WRC-12 but at the WRC-15 or WRC-18.

The other issue that needs an explanation is the diversity of views with regard to channel arrangements in the $700 \mathrm{MHz}$ band after the conference and the reason why most of 
the proposals of arrangements that in conflict with CEPT arrangements were withdrawn. The diversity is related to two perspectives. Firstly, for national regulators from the Arab and African countries, the success of their initiations at the WRC-12 encouraged these countries to participate actively in the discussion related to frequency arrangements of the allocated $700 \mathrm{MHz}$ band. Their focus was on partially or fully deploying the APT plans in their countries. Secondly, for the industry (mainly operators), they were focusing on having the largest spectrum bandwidth in the $700 \mathrm{MHz}$ band for mobile operators even if that does not protect the broadcasting service in the adjacent spectrum band. Moreover, withdrawing these proposals could be explained by that decisions related to spectrum allocation cannot be taken exclusively by national regulators or the industry. While the former do not have the manufacturing base to take decisions on behalf of the industry except in cases where there is a quite large market (e.g. China), the later may not see the whole picture which accommodates other services such as broadcasting.

In the attempt to examine the Arab and African proposal, it is found that UAE was the first initiator of the $700 \mathrm{MHz}$ issue and then it started to get support from the Gulf countries and then from the rest of the Arab countries and then from the African countries. It is argued also that the leading role that UAE regulator played in the WRC-12 was not based on the industry requirement in UAE. For instance, UAE operators have an average of more than 140 $\mathrm{MHz}$ of FDD spectrum which is one of the highest values in the world comparing to European countries such as Germany which has an average of less than $80 \mathrm{MHz}$ of FDD spectrum per operator (Deloitte LLP, 2013). Therefore, it is argued that the UAE proposal was supported and initiated by the UAE government which wanted to take an international leading role. More specifically, there is intersection between the UAE spectrum policy and the market in what is called "State Capitalism" in which "the government "encourages" investment in chosen technologies, in some cases with government-controlled funding and coordinates spectrum policy to match the investments" (Marcus, 2013). For instance, UAE government owns $39.5 \%$ of the first mobile operator, Etisalat Company, and $50 \%$ of the second mobile operator, Du Company (BMI, 2013a; BMI, 2013b). There is also similarity between European and Arab countries in terms of adopting state capitalism in spectrum policy (Marcus, 2010) and this could explain why the European countries eventually agreed to the $700 \mathrm{MHz}$ proposal. For instance, the German government owns $31.94 \%$ of Deutsche Telekom (Deutsche Telekom AG, 2013).

One other issue that needs careful examination is the role of WRC-12 chairman in the discussion. As one of the main proponents of the $700 \mathrm{MHz}$ proposal is UAE and also the chairman of WRC-12 was elected at the beginning of the conference from UAE (ITU-R, 2012d) which is also the chairman of ASMG (ASMG, 2008), this put more focus on the neutrality of the conference chairman as he could adopt different approaches when an issue like that emerges. One option would be not to intervene in the discussions and to coordinate a voting whether to discuss the issue or not. Instead, the chairman called for a meeting accommodating the representatives of the ITU-R regional organisation groups to resolve the issue. Furthermore, the WRC-12 chairman submitted a proposal to the conference to reach a compromise between the regional organisations regarding the issue (Standeford, 2012b). Moreover, the WRC-12 chairman got the ITU-R BR involved and asked for advice, and the reply from the BR was that WRCs are sovereign and can discuss any issue without being one of its agenda items. Besides, while the industry was aware of the UAE proposal before the WRC-12, the selection of the conference chairman from UAE encouraged the industry to back up the $700 \mathrm{MHz}$ proposal because the chairman may have the ability to control the debate. 
Through the history of the last recent WRCs, there is only one known record of discussing and approving an issue that is not on the agenda of the conference. That was in WRC-95 when the conference allocated $400 \mathrm{MHz}$ in the spectrum bands 19 and $29 \mathrm{GHz}$ to non-geostationary fixed-satellite service networks subject to a large number of reservations (ITU-R, 1995; ITU, 1996). While the issue was not on the agenda of the conference (ITU Council, 1994), however, the conference decided to discuss the issue under the pressure of operator of US-Based low-orbit satellite networks, namely Teledesic (Radiocommunications Agency, 1997). One view on discussing the $700 \mathrm{MHz}$ without being one of the agenda items of the conference is that this was not addressed properly according to the ITU-R procedures. More specifically, the agenda of each WRC is proposed by the previous one by a resolution. This resolution is submitted to the council of the ITU to be approved. During WRC, the first decision of the conference should be related to the competency of the conference to deal with that additional item and after that the issue could be added to the conference agenda. This was not the case in the WRC-12.

Regarding the role of the ITU-R system in the $700 \mathrm{MHz}$ discussion, this article argues that the system is unintentionally in favour of the European countries as the discussions is based on the technical studies which are conducted in the ITU-R study groups prior to WRCs by technical experts from member states. These experts are mostly from the European countries in Region 1. Therefore, the influence of Arab and African countries in Region 1 is limited to the general policy areas which do not require technical expertise. It could be better for the Arab and African countries either to conduct the technical studies by themselves or to have a team from the ITU-R BR to address the technical issues on a non-biased basis. This is quite important as technical studies could end up with different results depending on whether it is based on restrictive simulation models or empirical studies.

However, the ITU-R system could be also argued to be in favour of the Arab and African countries during the WRCs. This is due that while before WRCs issues are studied individually in the concerned study groups, during WRCs, all the different issues on the agenda of the conference are discussed in parallel and sometimes by the same people. Therefore, some countries may use their bloc voting capabilities on issues that do not directly affect them so that they can trade positions afterwards on the concerned issues (U.S. Congress Office of Technology Assessment, 1982). In other words, the objection to some issues and the attempt to delay resolving these issue to the last days of the conference may be related to the resolution of other issues (United States Department of State, 2003).

\section{Policy Implications}

One of the main implications of the $700 \mathrm{MHz}$ issue is that it shows how the Asian market has become large enough so that not only Asian countries in Region 3 adopt the APT plan in the $700 \mathrm{MHz}$ but also Latin American countries in Region 2 and Arab and African countries in Region 1. This is in contrast to the situation before where CEPT plans used to be the first and maybe the only choice for the Arab and African countries. Moreover, it has become more important for the mobile industry to harmonise the frequency bands used for mobile services in order to reduce the cost of users' terminals (GSMA, 2012a). Meanwhile, with around two thirds of the world's population, the APT has the ability to lead the world in terms of frequency arrangements plans (GSMA, 2012c). This has put several European countries in difficult situation because the adoption of the CEPT band plan is mandatory within the EU (GSMA, 2012b). 
Moreover, many interviewees explain that the three regions system was only based on historical and political reasons. More specifically, at the early days of telecommunications, there were not so much inter-regional communications and there was also tension between the west and east. This is obvious from the international table of spectrum allocation which shows that the higher the frequency, the less differences between the three regions in terms of spectrum allocations (ITU-R, 2008) noting that higher frequencies were relatively allocated recently comparing to lower frequencies. In addition, it seems that Region 1 is the most complicated ITU-R region in terms of spectrum allocation harmonisation as it has four regional groups (ATU, ASMG, CEPT, and RCC). Moreover, it is argued that regional harmonisation between the ITU-R regional organisations becomes more important than the ITU-R traditional harmonisation within the three ITU-R regions.

The $700 \mathrm{MHz}$ issue has also shown clearly the need for more flexibility in priori planning conferences such as RRC-06 where each country submits its requirements. More specifically, while the GE06 agreement is similar to other previous regional agreements regarding broadcasting spectrum planning such as the Stockholm agreement of 1961 (ST61) and Geneva agreement of 1989 (GE89), what has changed is the pace of technology development which makes the life cycle of GE06 much smaller comparing to previous agreement. While the GE06 was agreed in 2006, it was influenced by allocating the band $790-862 \mathrm{MHz}$ to mobile service by the WRC-07 on co-primary basis in addition to the broadcasting service. Moreover, one interviewee explains that the WRC-07 decision paved the way for opening the $700 \mathrm{MHz}$ issue during the WRC-12. More specifically, the broadcasters called for establishing the JTG 5-6 at the WRC-07 to study the sharing issues between the mobile and broadcasting at the $800 \mathrm{MHz}$ hoping that they would restrict access of mobile operators to this band or reduce the allocation. However, it was a risky game as the JTG 5-6 outputs resulted in confirming the allocation and in proving that mobile service could be accommodated with the current GE06 plan without any additional measures.

Regarding the influence of the European countries in the ITU-R, most of the interviewees indicate that such influence is not in decline. Instead, it is the role of the Arab and African countries that has increased. "There have been big changes in the dominance of Region 1 after WRC12. The Arab states made a big role. For the first time in history the Arab countries lead the industry to specific road. The main issue here is that the balance of power has changed a little bit".

In addition, it seems that the European countries still have the upper hands with regard to decisions related to the industry as they are a major base of several international operators and manufactures that have operations in the Arab and African countries. Therefore, the decisions of the Arab and African countries cannot be enforced if it lacks the support of the industry. In addition, one view is that the European countries partially achieved what they want as they were targeting from the beginning discussing the issue at WRC-15 and this is what happened as the decision is effective after WRC-15 upon refinement of the lower edge of the band. In other words, CEPT was able to adapt to the situation and to make sure its position is in place.

However, one interviewee explains that the participation of European countries in the ITU-R study groups is in decline as these countries focus on the discussion at the EU level than at the ITU level which is more important for European member states. It is only few European countries that participate actively in the study groups' discussion such as France, Germany and the UK. Moreover, one interviewee points out that the fact that CEPT prepares ECPs and appoints one CEPT coordinator for each agenda item may be inflexible and 
inefficient during WRCs as it could be more efficient for CEPT to have individuals from the different European countries addressing the issue similar to the Arab and African countries.

In general, while we cannot describe the influence of the European countries in ITU$\mathrm{R}$ Region 1 as in decline, we can say that the credibility of the European countries is in question as they changed their positions with regard to the allocation of the bands 790-862 $\mathrm{MHz}$ and 694-790 MHz in WRC-07 and WRC-12 respectively.

It seems also that the main implication for the $700 \mathrm{MHz}$ issue is the increase of the African countries confidence regarding WRCs participation. More specifically, the African preparation for WRCs has changed significantly following the African success at the last WRC-12. For instance, the ATU has established a continental radio spectrum working group named Africa Spectrum Working Group (AfriSWoG) in 2013. AfriSWoG is composed of 19 Member States acting as a steering group based on weighted geographical representation of the different ATU regions and it aims at enhancing coordination in preparations for and participation at relevant international spectrum management conferences (ATU, 2013a). In addition, the African countries have started in modifying the GE06 frequency plan in order to accommodate the digital terrestrial broadcasting requirements in the band 470-694 MHz band (WP JTG 4-5-6-7 Chairman, 2013). The African countries succeeded in achieving 31 iterations in this process comparing to only 4 iterations that were conducted during the RRC06 that plan the GE06 agreement (South Africa (Republic of) et al., 2013).

Last but not least, what could be noticed from the $700 \mathrm{MHz}$ issue is the increasing role of the industry in the ITU-R activities since the ITU Plenipotentiary Conference of 1995 formally recognised the rights of the private sector (MacLean, 1995). The number of sector members, associates, and academia has increased in the last years to reach over 700 while the number of member states is 193 (ITU, 2013a). As explained in one of the interviews "The ITU-R used to accommodate dominant countries many years ago but now it accommodates dominant companies".

\section{Conclusions}

Since its establishment in 1865 , the ITU has been considered by many as a European organisation as it was controlled by small number of European countries. Due to the conflict of interests between the European countries and other countries of the world, the world was divided into three regions in terms of service allocation where the European, African and the Arab countries lie in Region 1.

Region 1 accommodates four regional organisations that present common proposal to the WRCs on behalf of their countries namely CEPT, APT, ASMG, and RCC. This article shows that decision making procedures in CEPT with regard to WRC are quite complex in contrast to the procedures in the Arab and African countries. Firstly, CEPT accommodates 48 countries with 28 of them present the interests of the EU. Secondly, the presence of some members of RCC in CEPT could be more problematic. Thirdly, the UK and France are members of CTO and CAPTEF respectively which are international organisations that accommodate several Arab and African countries. On the other hand, it seems that the procedures in the Arab and African countries may be less complicated and reaching agreement is relatively easier to achieve in these countries comparing to the European countries.

Recent years have witnessed a change in the power balance between the European countries on one side and the Arab and African countries on the other side especially during 
the last WRC-12 where the Arab and African countries called for an immediate allocation of spectrum in the 694-790 MHz band to mobile service to meet growing broadband demand noting that the issue was not on the agenda of the conference. The origin of the issue is related to the WRC-07 which decided to identify the 790-862 MHz band in Regions 1 for IMT and to conduct sharing studies in the band between the mobile service and other services which the frequency band is currently allocated to such as broadcasting service. The results of these studies at the WRC-12 showed that no new mandatory regulatory measures are needed to enable sharing between mobile and broadcasting services.

The Arab and African countries' proposal at WRC-12 was based mainly on that the 694-790 MHZ band is already allocated in ITU-R Regions 2 and 3 for mobile service which will decrease the cost of deploying such systems. CEPT and RCC opposed such proposal arguing that the issue is not on the agenda of the conference and that the band is heavily used by other services especially broadcasting. WRC-12 decided eventually to allocate the 694$790 \mathrm{MHz}$ frequency band in Region 1 to mobile service on a co-primary basis. The allocation is effective immediately after WRC-15 upon refinement of the lower edge of the allocation.

Following WRC-12, the European countries revisited their plans for the $700 \mathrm{MHz}$ band while considering deploying mobile service in it. However, they are facing pressure from the broadcasting industry. The discussion has continued in the ITU-R with regard to harmonising the different frequency arrangements among the three ITU-R regions considering that CEPT plan in the $800 \mathrm{MHz}$ overlaps with APT plan in the $700 \mathrm{MHz}$ band and that the main incentive for the Arab and African countries for proposing the $700 \mathrm{MHz}$ allocation in the WRC-12 was to harmonise their spectrum plans with Regions 2 and 3, specifically the APT plan. While there have been different proposals to maximise the utilisation efficiency of the band $694-790 \mathrm{MHz}$ even if that contradict with the CEPT plan, most of them were withdrawn later to focus on finding channel arrangements that could fit with the CEPT plan and partially with the APT plan while having one duplexer in the users handsets to achieve economy of scales

The analysis of the $700 \mathrm{MHz}$ issue shows that the preliminary European refusal to the $700 \mathrm{MHz}$ proposal at the early days of WRC-12 could be explained by the difficulty of releasing the $800 \mathrm{MHz}$ band for mobile service in the European countries and by the severe competition in the European mobile market. On the other hand, the diversity in the European views over the issue during the conference is related to the internationalisation of European telecom operators and manufactures, and the different needs with regard to terrestrial broadcasting service. Moreover, the conflict with regard to channel arrangements in the 700 $\mathrm{MHz}$ band after WRC-12 shows that decisions related to spectrum allocation cannot be taken exclusively by national regulators or the industry.

The examination of the Arab and African proposal shows that UAE was the first initiator of the $700 \mathrm{MHz}$ issue and then it started to get support from the other countries. In addition, the chairman of WRC-12 did play an important role in coordinating the discussion of the issue which encouraged the industry to support the proposal. Furthermore, the ITU-R system is found to be in favour of the European countries when it comes to technical studies prior to WRCs while it is in favour of the Arab and African countries during WRCs negotiations.

One of the main implications of the $700 \mathrm{MHz}$ is that it shows how the Asian market has become large enough so that not only Asian countries in Region 3 adopt the APT plan in the $700 \mathrm{MHz}$ but also Latin American countries in Region 2 and Arab and African countries in Region 1. This is in contrast to the situation before where CEPT plans used to be the first and maybe the only choice for the Arab and African countries. In addition, it is argued that 
regional harmonisation between the ITU-R regional organisations becomes more important than the ITU-R traditional harmonisation within the ITU-R three regions. Furthermore, the $700 \mathrm{MHz}$ issue has shown clearly the need for more flexibility in priori planning conferences such as RRC-06.

Regarding the influence of the European countries in the ITU-R, most of the interviewees indicate that such influence in Region 1 is not in decline. Instead, it is the role of the Arab and African countries that has increased. However, the European countries still have the upper hands with regard to decisions related to the industry.

\section{References}

APT 2009. UHF Band Usage and Considerations for Realizing the UHF Digital Dividend. The 7th APT Wireless Forum Meeting. Phuket.

APT 2010. APT Report on Harmonized Frequency Arrangements for the Band 698-806 MHz. 9th APT Wireless Forum Meeting. Seoul.

APT. 2013. APT Conference Preparatory Group for WRC-15 (APG-15) [Online]. Available: http://www.apt.int/ [Accessed 18/8 2013].

ASMG 2007. Arab States Common Proposals. Common Proposals for the Work of the Conference. Agenda Item 1.4. World Radiocommunication Conference (WRC-07). Geneva.

ASMG 2008. Report of the 11th Meeting of ASMG. Dubai.

ASMG 2010. ASMG Preliminary Positions on the Agenda Items of the WRC-12. 2nd ITU Information Meeting on WRC-12 Preparation. Geneva.

ASMG 2011. Arab States Common Proposals. Common Proposals for the Work of the Conference. Agenda Item 1.17. World Radiocommunication Conference (WRC-12). Geneva.

ASSOCIATION OF PROFESSIONAL WIRELESS PRODUCTION TECHNOLOGIES (APWPT) 2012. Cultural Europe Will Not Survive A Second Digital Dividend.

ATU 2007. African Common Proposals for the Work of the Conference. Agenda Item 1.4. World Radiocommunication Conference (WRC-07). Geneva.

ATU 2011a. African Common Proposals for the Work of the Conference. World Radiocommunication Conference (WRC-12). Geneva.

ATU 2011b. Recommendations. ATU Digital Migration and Spectrum Policy Summit. Nairobi.

ATU 2012. African Common Proposals for the Work of the Conference. Agenda Item 1.17. World Radiocommunication Conference (WRC-12). Geneva.

ATU. 2013a. Africa Spectrum Working Group (AfriSWoG) [Online]. Available: http://www.atu-uat.org/ [Accessed 18/8 2013].

ATU. 2013b. History [Online]. Available: http://www.atu-uat.org/ [Accessed 18/8 2013]. BILLQUIST, S. 2010a. European Pressure Grows for 2016 Global IMT Spectrum Action. PolicyTracker.com [Online]. [Accessed 30/6/2012].

BILlQUIST, S. 2010b. Mobile Industry to Press Spectrum Needs in 2016 World Conference Preparations. PolicyTracker.com [Online]. [Accessed 30/4/2012].

BMI 2013a. Emirates Integrated Telecommunication Company (du) - Q1 2013 (Company Profile Article).

BMI 2013b. Emirates Telecommunications Corporation (Etisalat) - Q1 2013 (Company Profile Article). 
BROADCAST NETWORKS EUROPE. 2011. Broadcast Networks Europe response on the public consultation on the draft RSPG opinion on common policy objectives for WRC12 [Online]. Available: http://rspg-spectrum.eu/ [Accessed 20/8 2013].

BRYMAN, A. \& BELL, E. 2007. Business research methods., New York, Oxford University Press.

CEPT 2007. European Common Proposals for the Work of the Conference, Part 4, Agenda Item 1.4. World Radiocommunication Conference (WRC-07). Geneva.

CEPT. 2011. CPG-12-8 [Online]. Available: http://www.cept.org/ [Accessed 2013 18/8].

CEPT. 2013. Member Countries and Year of Admission [Online]. Available: http://www.cept.org/ [Accessed 18/8 2013].

CHADUC, J. \& POGOREL, G. 2008. The Radio Spectrum.Managing a Strategic Resource, London, ISTE Ltd.

CIG. 2013. About CIG [Online]. Available: http://www.commonwealthitugroup.org/ [Accessed 18/8 2013].

CONTANT, C. M. \& WARREN, J. 2003. The World Radiocommunication Conferences Process: Help or Hindrance to New Satellite Development? Acta Astronautica, 53.

CULLEN INTERNATIONAL 2011. EU Spectrum Policy: Digital dividend. 33rd Meeting of EPRA. Ohrid.

DELOITTE LLP 2013. Arab States Mobile Observatory 2013.

DEUTSCHE TELEKOM AG. 2013. Shareholders Structure [Online]. Available: www.telekom.com [Accessed 18/8 2013].

EBU. 2011. The EBU response to the Public consultation on the draft RSPG Opinion on Common Policy Objectives for WRC-12 [Online]. Available: http://rspgspectrum.eu/ [Accessed 20/8 2013].

EUROPEAN COMMISSION 2011. European Parliament resolution of 15 September 2011 on the European Union's policy approach to the ITU World Radiocommunication Conference 2012 (WRC-12). Official Journal of the European Union.

FOURNIER, E. 2011. WRC-12 Preparation-CEPT.

FOURNIER, E. 2012. WRC-12: A Success for CEPT? ECC Newsletter [Online], February.

FRANSMAN, M. 2010. The New ICT Ecosystem: Implications for Policy and Regulation, Cambridge University Press.

GSMA 2012a. Draft Position Paper for Latin America on Digital Dividend/UHF Band Plans.

GSMA 2012b. Position Paper for Africa on Digital Dividend/UHF band Plans.

GSMA 2012c. Position paper for Asia Pacific on Digital Dividend/UHF band plans.

INTERNATIONAL ORGANISATION DE LA FRANCOPHONIE. 2013. 77 États et gouvernements [Online]. Available: http://www.francophonie.org/ [Accessed 18/8 2013].

ITU-ARAB REGIONAL OFFICE. 2003. Permanent Arab Spectrum Management Group (ASMG) [Online]. Available: ituarabic.org [Accessed 18/8 2013].

ITU-R 1995. WRC-95 Resolution 121. Development of Interference Criteria and Methodologies for Coordination between Feeder Links of Non Geostationary Satellite Networks in the Mobile Satellite Service and Geostationary Satellite Networks in the Fixed Satellite Service in the Bands 19.3 - $19.6 \mathrm{GHz}$ and 29.1 29.4 GHz. Provisional Final Acts - World Radiocommunication Conference (WRC95).

ITU-R 2003. Resolution 228 (Rev.WRC-03) - Studies on frequency-related matters for the future development of IMT 2000 and systems beyond IMT 2000 as defined 
by ITU-R. Provisional Final Acts - World Radiocommunication Conference (WRC03).

ITU-R 2007a. CPM Report on Technical, Operational and Regulatory/Procedural Matters to be Considered by the 2007 World Radiocommunication Conference.

ITU-R 2007b. Resolution 805. Agenda for the 2011 World Radiocommunication Conference. Provisional Final Acts - World Radiocommunication Conference (WRC07).

ITU-R 2007c. WRC-07 Resolution 749: Studies on the Use of the Band 790-862 MHz by Mobile Applications and by Other Services. Provisional Final Acts - World Radiocommunication Conference (WRC-07).

ITU-R 2008. Article 5: Frequency Allocations. Radio Regulations.

ITU-R 2010. ITU-R Report SM.2093-1: Guidance on the Regulatory Framework for National Spectrum Management.

ITU-R 2012a. ITU-R Recommendation M.1036-4: Frequency Arrangements for Implementation of the Terrestrial Component of International Mobile Telecommunications (IMT) in the Bands Identified for IMT in the Radio Regulations (RR). M Series. Mobile, Radiodetermination Amateur and Related Satellite Services.

ITU-R 2012b. WRC-12 Resolution 232. Use of the Frequency 694-790 MHz by the Mobile, Except Aeronautical Mobile, Service in Region 1 and Related Studies. Provisional Final Acts - World Radiocommunication Conference (WRC-12).

ITU-R. 2012c. WRC-12 Weekly Highlights. [Accessed 19/3/2012].

ITU-R. 2012d. WRC-12 Weekly Highlights. [Accessed 19/3/2012].

ITU. 1996. WRC-95: A New Approach. ITU News [Online].

ITU 2011. 3rd African Group Preparatory Meeting for WRC-12, Geneva, 9 November 2011.

ITU. 2013a. Membership [Online]. Available: www.itu.int [Accessed 15/8/2013.

ITU. 2013b. The second digital dividend: Another bite for mobile? ITU News [Online].

ITU COUNCIL 1994. Agenda for the World Radiocommunication Conference (WRC-95).

KIRKALDY, N. 2011. Mobile Broadband. ATU Digital Migration and Spectrum Policy Summit. Nairobi.

LIN, C. H. 2003. Regionalism or Globalism? Telecommunication Cooperation in EU. Australian International Law Journal, 95.

LYONS, P. 2011. Harmonization and The Economic Impact of Digital Dividend Spectrum in Sub-Saharan Africa. ATU Digital Migration and Spectrum Policy Summit. Nairobi.

MACLEAN, D. 1995. A New Departure for the ITU: An Inside View of the Kyoto Plenipotentiary Conference. Telecommunications Policy, 19.

MARCUS, M. 2010. Wireless Innovation and Interference. SpectrumTalk [Online]. Available: http://www.marcus-spectrum.com/.

MARCUS, M. 2013. IEEE-USA Petition to FCC on Speeding >95 GHz Deliberations Under Terms of 47 USC 157. SpectrumTalk [Online]. Available: http://www.marcusspectrum.com/.

MAZAR, H. 2009. An Analysis of Regulatory Frameworks for Wireless Communications, Societal Concerns and Risk: The Case of Radio Frequency (RF) Allocation and Licensing. PhD, Middlesex University.

MEYER, C. B. 2001. A Case in Case Study Methodology. Field Methods, 13. 
MOBILE EUROPE. 2012. Why WRC12 Could be the Most Important Conference for Mobile Industry This Year. MobileEurope [Online]. Available: http://www.mobileeurope.co.uk/.

NIGERIA 2012. Proposal for the Work of the Conference. Agenda Item 1.17. World Radiocommunication Conference (WRC-12). Geneva.

OBERST, G. 2012. EU and the Results of the WRC-12 (The Space Perspective). International Regulations of Space Communications: Current Issues. University of Luxembourg.

OFCOM 2012a. Securing Long Term Benefits from Scarce Spectrum Resources. A strategy for UHF bands IV and V.

OFCOM 2012b. UK Report of the ITU World Radio Conference (WRC) 2012.

POLITIS, C. \& WIJTING, C. 2010. Spectrum Issues in the Post WRC'07 Era. WWRF WG8 on Spectrum Topics.

RADIOCOMMUNICATIONS AGENCY. 1997. World Radiocommunication Conference 1995. Radiocommunications Agency Business Review 95/96 [Online]. Available: http://www.ofcom.org.uk.

RANCY, F. 2012. Outcome of WRC-12 for Mobile Broadband. Middle East Spectrum Conference 2012. Bahrain.

RCC. 2013. About RCC [Online]. Available: http://www.en.rcc.org.ru/ [Accessed 8/18 2013].

RSPG 2009. Draft SRPG Opinion on the Coordination of of EU Spectrum Interest: Part1: Preparation of ITU World Radiocommunication Conference.

RSPG 2012. Commission Services' Discussion Paper on the Future Use of the $700 \mathrm{MHz}$ Band in the European Union.

RYAN, P. S. 2005. European Spectrum Management Principles. Journal of Computer and Information Law, XXIII.

RYAN, P. S. 2012. The ITU and the Internet's Titanic Moment. Stanford Technology Law Review, 8.

SAUNDERS, M., LEWIS, P. \& THORNHILL, A. 2009. Research Methods for Business Students (5th edn.), Pearson Education Limited.

SHAHIN, J. 2011. The European Union's Performance in the International Telecommunication Union. Journal of European Integration, 33.

SOUTH AFRICA (REPUBLIC OF), A. R. O., BOTSWANA (REPUBLIC OF), KENYA (REPUBLIC OF), LESOTHO (KINGDOM OF), MALAWI, , MOZAMBIQUE (REPUBLIC OF), N. R. O., UGANDA (REPUBLIC OF), DEMOCRATIC REPUBLIC OF THE CONGO, SWAZILAND (KINGDOM OF), \& TANZANIA (UNITED REPUBLIC OF), Z. R. O., ZIMBABWE (REPUBLIC OF), 2013. Proposals for Lower Band Edge for the Band Being Studied under WRC-15 Agenda Item 1.2, Taking into Account Results of Work Done by ATU Member States towards Modification of the GE06 Plan. Meeting of Third Meeting of Joint Task Group 4-5-6-7. East London.

STANDEFORD, D. 2012a. Mobile Broadband in 700 MHz Band "Irresistible", Says RSPG Chief PolicyTracker.com [Online]. [Accessed 30/4/2012].

STANDEFORD, D. 2012b. WRC-12 Edges Towards Agreement on Mobile Broadband. PolicyTracker.com [Online]. [Accessed 30/4/2012].

STIRLING, A. 2012. Africa is Pushing Ahead in the Race for $700 \mathrm{MHz}$. International Journal of Digital Television, 3.

TELLIS, W. 1997. Application of a Case Study Methodology. The Qualitative Report, 3.

THE COMMONWEALTH. 2013. Commonwealth Telecommunications Organisation (CTO)

[Online]. Available: http://www.thecommonwealth.org/ [Accessed 18/8 2013]. 
THE WORLD BANK 2011. The Little Data Book on Information and Communication Technology 2011.

THE WORLD BANK. 2012. Country and Lending Groups [Online]. Available: http://data.worldbank.org.

U.S. CONGRESS OFFICE OF TECHNOLOGY ASSESSMENT 1982. Radiofrequency Use and Management: Impacts From the World Administrative Radio Conference of 1979.

UAE, QATAR \& KUWAIT 2011. Contribution Regarding the WRC-12 Activities: Agenda Item 1.17. ASMG 15th Meeting.

UNDATA. 2012a. Occupied Palestinian Territory [Online]. Available: data.un.org [Accessed 30/10/2012.

UNDATA. 2012b. Somalia [Online]. Available: data.un.org [Accessed 30/10/2012.

UNITED STATES DEPARTMENT OF STATE 2003. United States Delegation Report: World Radiocommunication Conference 2003.

UPU. 2013. RCC Members [Online]. Available: http://www.upu.int/ [Accessed 18/8 2013].

WP 5D CHAIRMAN 2013a. Chapter 04 - Meeting Report of Working Group Spectrum Aspects. Meeting of Working Party 5D (Sapporo, Japan 10 -17 July 2013). Sapporo.

WP 5D CHAIRMAN 2013b. Chapter 04 - Meeting Report of Working Group Spectrum Aspects. Meeting of Working Party 5D (Geneva, 30 January to 6 February 2013). Geneva.

WP JTG 4-5-6-7 CHAIRMAN 2013. Report of the Third Meeting of Joint Task Group 4-56-7. Meeting of Third Meeting of Joint Task Group 4-5-6-7. East London.

ZACHER, M. W. 1996. Governing Global Networks: International Regimes for Transportation and Communications, Cambridge University Press. 